\title{
An Empirical Study on the Stock Price Volatility of Small and Medium Enterprise Board in China
}

\author{
Qishui $\mathrm{Chi}^{1} \&$ Jieyi Huo ${ }^{1}$ \\ ${ }^{1}$ Business School, Shantou University, Shantou, Guangdong, China \\ Correspondence: Jieyi Huo, Business School, Shantou University, Shantou 515063, Guangdong, China. E-mail: \\ 14jyhuo@stu.edu.cn
}

Received: October 4, 2017

Accepted: October 19, 2017

Online Published: November 16, 2017

doi:10.5430/rwe.v8n2p12

URL: https://doi.org/10.5430/rwe.v8n2p12

\begin{abstract}
This article utilizes structural change method to examine the fluctuation characteristics of stock prices of China's small and medium enterprises. This study indicates that time series of Chinese small and medium-sized enterprises stock prices are not characterized by mean reversion. Therefore, the policy bailouts in the market including the rescue package of the government in June 2015 are ineffective because they are offset by other factors. The long-run growth of stock prices depends on the supply and demand situation in capital market as well as the growth of national economy but has no connection with the policy bailouts.
\end{abstract}

Keywords: random walk, mean reversion, SME Board, stock prices, policy bailout

JEL Classification: C1; C5; G1

\section{Introduction}

The Small and Medium Enterprise Board (SME Board) in A-share market is an important composition of China multi-level capital market. In June 2004, the first batch enterprises like Zhejiang NHU Co., Ltd (NHU) et al start to be traded in the secondary market of SME Board. The steps of raising capital through equity market have been speeding up since June 2005 .

The issue whether stock prices in a specific market can be characterized by following a random walk or mean reverting process has a great impact on investors investment strategies. Besides, it also influences the effectiveness of policies implemented in stock markets. Over a long period, scholars strive to study the efficiency of stock markets but overall results are inconclusive. Specifically, if stock prices are characterized by random walks, future stock prices are unpredictable. Investors cannot gain abnormal profits through technical analysis or fundamental analysis and policies implemented by government officials cannot change the way stock prices grow. However, if stock prices are mean-reverting, there is a basis for investors forecasting future movements of stock prices. Simultaneously, government officials can implement policies to govern stock markets.

There has been a considerable empirical research examining the efficiency of various stock markets. Taking one structural break in the series into consideration, Narayan and Smyth (2005) apply the sequential trend break proposed by Zivot and Andrews (1992) and panel data unit root tests proposed by Im et al. $(2002,2003)$ to examine whether stock prices of 22 OECD countries can be characterized by mean reversion or random walks. The result indicates these stock price series follow random walk process. Later, Narayan and Smyth (2006) obtain the same result when they utilize multiple trend break unit root tests and use data of monthly stock prices of 15 European countries. A serial correlation test, a runs test, an Augmented Dickey-Fuller (ADF) test and the multiple variance ratio test are utilized by Borges (2011) to test the efficiency of the Lisbon stock market from January 1993 to December 2006. The results show Portuguese stock market index can be represented as random walk. Clark and Coggin (2011) use the semiparametric GPH method to examine the properties of real monthly U.S. stock returns from 1871 to 2003 and the results reveal the permanent (random walk) component of stock prices is dominant. Recently, Chattopadhyay (2016) utilizes the modified versions of ADF (viz., PP, ZA \& CMR) tests to study the volatility of stock prices in Indian market and the test results are in favour of the null hypothesis of unit root, which indicates Indian stock market follow random walk process from January 1995 to July 2015.

On the other hand, Balsara et al (2007) discover Chinese stock market is characterized by mean reversion after they use the variance ration test to analyse the index of daily stock prices for all class A- shares from December 19, 1990 
to June 27, 2005 and class B-shares from February 21, 1992 to June 27, 2005 traded on both the Shanghai and Shenzhen stock exchanges of China. Using the Markov regime-switching framework, Shen and Holmes (2014) explore if stock prices in 12 Asia-Pacific countries can be characterized by a random walk and find the presence of two stationary regimes with different speeds of adjustment in each of the 12 Asia-Pacific countries. Using the daily data of Bombay Stock Exchange (BSE)-200 index-based companies over the period of 1 January 1991 to 31 December 2012, Dsouza and Mallikarjunappa (2015) apply runs test, augmented Dickey-Fuller test (ADF) Test, Phillips-Perron test (PP) test, autocorrelation test and generalized autoregressive conditional heteroscedasticity (GARCH) $(1,1)$ model to test the efficiency of Indian market. They find Indian stock market is not weak-form efficient. Mishra et al (2015) use unit root tests allowing the presence of structural breaks and heteroskedasticity in the data to test the efficiency of Indian market and conclude Indian stock indexes are mean reverting.

Meanwhile, some studies show contradicted results. Chang and Ting (2000) apply a variance-ratio test to study the volatility in Taiwan's stock price index for the period of 9 January 1971 to 6 January 1996. In this study, the null hypothesis of random walk is rejected using weekly value-weighted market index, but the random walk hypothesis cannot be rejected with monthly, quarterly and yearly value-weighted market indexes. Hooi and Smyth (2007) gain contradictory results when they apply univariate and panel Lagrange Multiplier (LM) unit root tests with one and two structural breaks to discover the properties of stock prices in eight Asian countries from 1 January 1991 to 30 June 2005. When the univariate LM unit root tests and panel LM unit root are tested with one structural break, the results show stock prices in each country is characterized by a random walk. However, the results show stock prices in these eight countries are mean-reverting when two structural breaks are involved. In addition, Lakshmi and Roy (2012) use Box Pierce Q-Statistics, Ljung-Box (LB) statistics, Augmented Dickey-Fuller (ADF) as well as Lo and MacKinlay (1988) variance to test the random walk hypotheses using daily, weekly and monthly returns of six Indian stock market indices from January 2000 to October 2009. They obtain disparate results when they use different methods. The share indexes do not follow random walks when applying the former three methods while the stock prices are characterized by random walks when applying Lo and MacKinlay (1988) variance ratio test under the assumptions of both homoskedasticity and heteroskedasticity. Furthermore, under different assumptions, Shirvani and Delcoure (2016) find contradict results when they use heterogeneous panel unit root tests developed by Im et al. $(1997,2003)$ and Pesaran (2007) to test the presence of unit root in the real stock prices of 18 OECD countries for the 1985-2013 period.

The view that many macroeconomic series are random and non-stationary is dominant in academia of the study of stationarity for around ten years since Dickey and Fuller (1979) raise ADF test (Perron, 1989). Nelson and Plosser (1982) utilize Dickey and Fuller test $(1979,1981)$ to analyse 14 annual time series (NP series) including real and nominal GDP in US. The results show 13 out of 14 long-term annual macro series follow unit root process. Chow (1960) and Perron (1989) set observed structural breaks through discrete events, which is questioned by other scholars because of faults of "observed" behaviour and thus Chow test cannot be employed when break points present in time series are unknown. Zivot and Andrew (1992) extend the test of exogenous observed break points (Perron, 1989) to unconditional unit-root test, which is the test of endogenous break points. Zivot and Andrew (1992) also utilise Monte Carlo test to gain asymptotic critical values and find the null hypothesis of unit root is rejected at $5 \%$ significant level in six out of the seven NP series and the other fails to reject at $10 \%$ significant level.

Lumdaine and Papell (1997) extend endogenous test to multiple break points but still use NP series. At 5\% significant level, they reject the null hypothesis of unit root for 7 NP series while they reject the null hypothesis of unit root at $10 \%$ significant level for $9 \mathrm{NP}$ series. The amount of time series they reject are between that of Perron (1989) and that of Zivot and Andrews (1992). Particularly, Lumsdaine and Papell mention the null hypothesis of unit root is rejected anew at 5\% significant level for 3 out of 7 NP series. For these 7 NP series, the null hypothesis is rejected by Perron (1989) but fail to be rejected by Zivot and Andrews (1992).

So far, the issue of distinguishing the number of endogenous break points automatically has not been settled. Nevertheless, there some achievements in the research on types of break points. Lumsdaine and Papell (1997) raise AA, CA and CC models utilized NP series to estimate, which are based on model A (mean drift model), model B (trend drift model) and model C (mean and intercept drift model). Henceforth, model AA, CA and CC are widely used in the tests of break points, including Ben-David, Lumsdaine and Papell (2003), Papell and Prodon (2007) et al. Wang et al (2009) deem that model AA, CA and CC used by Lumsdaine and Papell (1997) cannot describe the properties of time series completely and thus add model BB, CB and AB. Chi and Wang (2013) find the operation of difference has same impact on series following random walks and series characterized by mean reversion, which indicates that it saves information of series changes in the short term but the information deleted or lost are different. Hence, if results of unit root test indicate the series are non-stationary, further break points test on structural change 
should be implemented to decide if the series follow random walks process. Chi and Wang (2013) apply method of Lumsdaine and Papell to study the properties of time series such as time series of broad money of China.

The main contribution of this paper is the study on the volatility of SME Board based on structural change theory. To our knowledge, it is the first paper that explores the volatility of SME Board from structural change angle because scholars tend to focus on the main board in China. The SME Board has provided an important financing channel to small and medium-sized enterprises since June 2005, which is an important composition of Chinese capital market. Therefore, this change in recent ten years should be noticed when studying the issue of volatility in Chinese stock market. It is the first time for us to apply the method of structural change to study the fluctuation of stock prices in this emerging market. To ensure the consummation of the empirical result, in this study, we not only use the three sub-models proposed by Lumdaine and Papell (1997), which are used to search break points, but also utilize another three sub-models proposed by Wang et al (2009). In addition, to ensure the accuracy of the empirical result, we conduct mass Monte Carlo operation. We obtain the critical value of break point test at different significant levels after the cycling computing of each sub-model for 10,000 times respectively.

Besides, we offer a new angle to evaluate the government's intervening behaviour in the stock market. We consider structural change method can be used to the study of government policy evaluation. In June 2015, to restrain the stock pricing plummeting, Chinese government implement a powerful rescue package. Some methods are unprecedented, for example, prohibiting institutions from shorting stock, etc. Scholars hold different judgement on the effect of government's rescue package. The result of this paper indicates stock prices in SME Board follow a random walk process. Expressly, the intervening behaviours in the market including the rescue package of the government in June 2015 are ineffective because they are already offset by other factors. The long-run growth of stock prices depends on the supply and demand situation in equity market as well as the growth of national economy but has no connection with other events.

Certainly, the defect in our study is the limit in SME Board, which will weaken the power of this study. We are supposed to study the volatility of all stock markets in China to evaluate the effect of government's rescue package, including Shanghai and Shenzhen A-share and B-share stock markets, the Growth Enterprises Markets, etc.

This article is organized as follows. Section II describes the methodologies and data processing. Section III presents the value of one-tailed test based on analogue simulation. Section IV discusses the empirical results. The conclusion appears in section $\mathrm{V}$.

\section{Methodology and Data}

From literature mentioned above, we can know that the theoretical sources of tests on structural change in time series done by Chi and Wang (2013), Wang et al (2009) are the study of Lumsdaine and Papell (1997). The difference is Wang et al (2009) extend test types of Lumsdaine and Papell (1997) and add sub-model BC, BA and BB, which make tests of multiple breaks incline to be more comprehensive and consummate. In accordance with methodologies of Lumsdaine and Papell (1997) and the supplement of Wang et al (2009), this paper arranges the test on structural change on time series in stock prices from SME Board as bellow.

Firstly, the null hypothesis and alternative hypothesis are as follows.

$$
\begin{aligned}
& \mathrm{H}_{0}: \alpha=0 \\
& \mathrm{H}_{1}: \alpha<0
\end{aligned}
$$

Secondly, the model testing structural change and multiple break points is show as follows.

$$
\Delta s p_{t}=\alpha s p_{t-1}+\mu+\beta t+\theta D U 1_{t}+\gamma D T 1_{t}+\omega D U 2_{t}+\psi D T 2_{t}+\sum_{i=1}^{p} c_{i} \Delta s p_{t-i}+e_{i}
$$

$D U 1_{t}$ and $D U 2_{t}$ in the model above represent mean abrupt change happening in different time, while $D T 1_{t}$ as well as $D T 2_{t}$ indicate trend abrupt change arising in different time.

In accordance with equation (1), we can obtain another 5 models testing structure abrupt change via the combination of multiple break points.

$$
\begin{gathered}
\Delta s p_{t}=\alpha s p_{t-1}+\mu+\beta t+\theta D U 1_{t}+\gamma D T 1_{t}+\psi D T 2_{t}+\sum_{i=1}^{k} c_{i} \Delta s p_{t-i}+e_{i} \\
\Delta s p_{t}=\alpha s p_{t-1}+\mu+\beta t+\theta D U 1_{t}+\gamma D T 1_{t}+\omega D U 2_{t}+\sum_{i=1}^{k} c_{i} \Delta s p_{t-i}+e_{i} \\
\Delta s p_{t}=\alpha s p_{t-1}+\mu+\beta t+\gamma D T 1_{t}+\psi D T 2_{t}+\sum_{i=1}^{k} c_{i} \Delta s p_{t-i}+e_{i} \\
\Delta s p_{t}=\alpha s p_{t-1}+\mu+\beta t+\theta D U 1_{t}+\psi D T 2_{t}+\sum_{i=1}^{k} c_{i} \Delta s p_{t-i}+e_{i} \\
\Delta s p_{t}=\alpha s p_{t-1}+\mu+\beta t+\theta D U 1_{t}+\omega D U 2_{t}+\sum_{i=1}^{k} c_{i} \Delta s p_{t-i}+e_{i}
\end{gathered}
$$


We can obtain estimated value of $\alpha$ by applying OLS regression to equation (1) - (6) and conduct significance test on $\widehat{\alpha}$. Record $t$ statistics of $\widehat{\alpha}$ as $t_{\widehat{\alpha}}$ and obtain the minimum value $t\left[\lambda_{\text {inf }}^{i}\right]=\inf _{\lambda \epsilon \Lambda} t_{\widehat{\alpha}^{2}}(\lambda)$ from set of $t_{\widehat{\alpha}}$. Compare $\inf _{\lambda \in \Lambda} t_{\widehat{\alpha}^{2}}(\lambda)$ with critical value gaining from analogue simulation and the null hypothesis of the test is $\mathrm{H}_{0}: \alpha=0$.

The initial data is obtained from Wind database. At present, the main indexes that represent the overall stock price level of SME Board are SZSE SME Price index (SSPI), SZSE SME Comp Index (SSCI), SMA Prime Mkt Index (SPMI) et al. SSPI is a comprehensive index and the sample in the index are stocks traded on SME Board. The sample of SSPI change to 100 stocks traded on SME Board after 30th June 2008. SSCI is similar to SSPI but SSCI has larger sample which includes 852 stocks in 2017. Both the basis period of SSCI and SSPI is 7th June 2005 and the basis point is 1000 . Nevertheless, the basis point of SPMI is still 1000 but it has later basis period, which is 30th December 2005. The compiling of SPMI use the method of market coverage rate and select $85 \%$ companies with largest market value traded on SME Board to compose the sample.

We utilize Census 12 to seasonally adjust SSPI, SSCI and SPMI series. The method of Census12 consists of model of addition, multiplication, logarithmic addition and pseudo-addition. The seasonal fluctuation of SSPI, SSCI and SPMI is proportionate to the change of original sequence, so we select multiplication model to seasonally adjust the data, which matches the properties of stock indexes. On this basis, we obtain the natural logarithmic of these three indexes after they are eliminated seasonal factor.

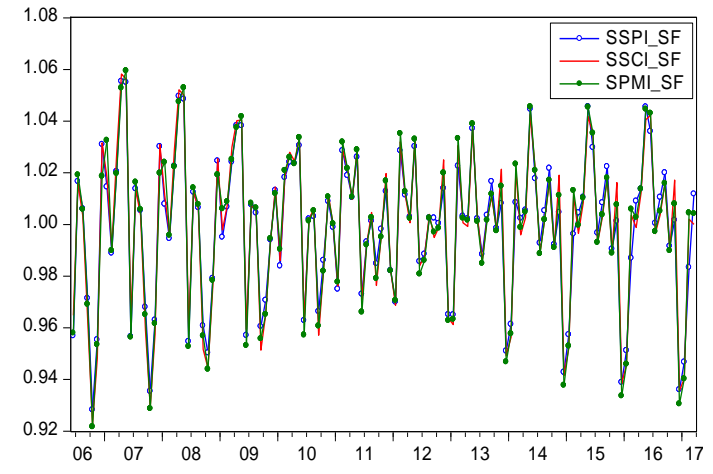

Figure 1. Seasonal Factor

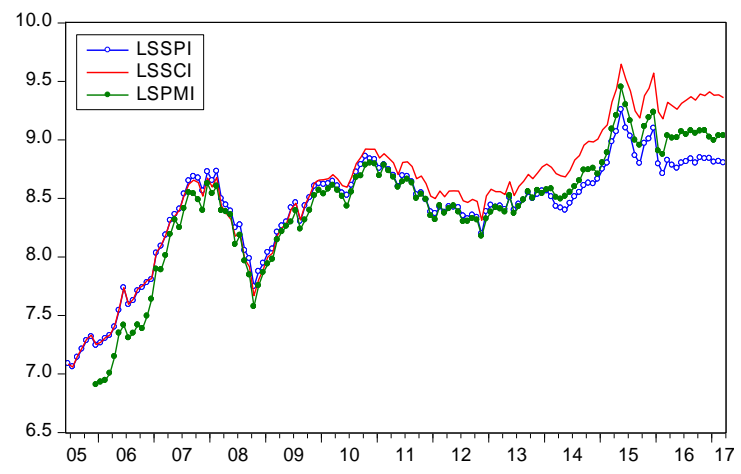

Figure 2. The natural logarithm of nominal indexes

We deem that the volatility in stock prices is affected by inflation. China Commodity Price Index (CCPI) covers 26 commodities in 9 categories like energy, steel, mineral products, nonferrous metals, rubber et al, which has a close relationship with the operation of small and medium-sized enterprises. The compiling of CCPI uses weighted average method, which regards June 2006 as basis point (100). This paper employs CCPI published by the Ministry of Commerce to eliminate inflation factor in stock prices and obtains real stock price logarithmic series LRSSPI, LRSSCI and LRSPMI. The period of the sample covers from June 2006 to March 2017 since CCPI is published from June 2006.

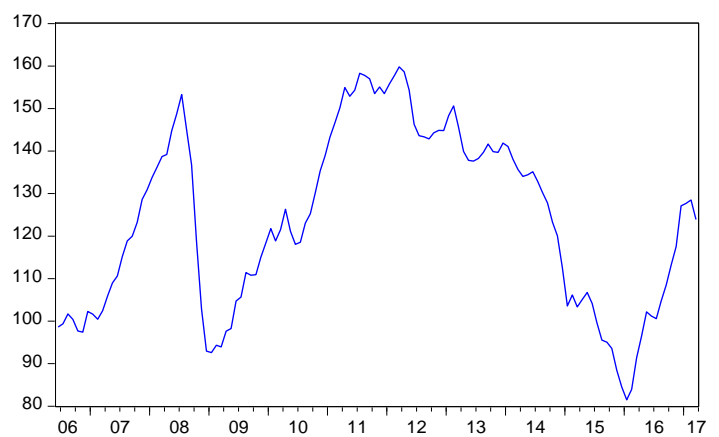

Figure 3. China Commodity Price Index (CCPI)

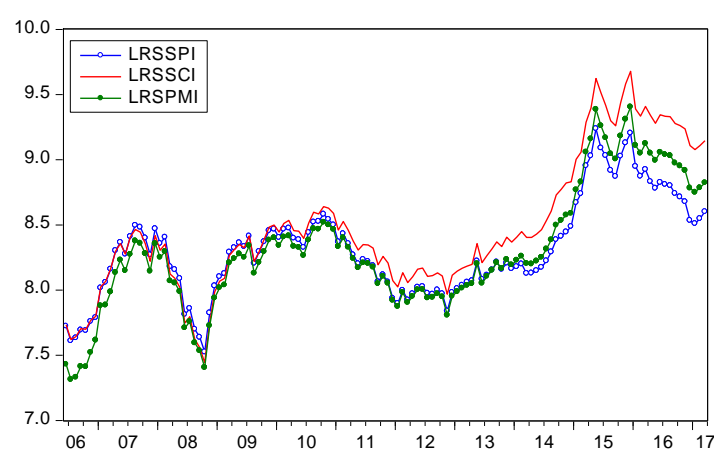

Figure 4. The natural logarithm of real indexes 


\section{The Value of One-tailed Test Based on Analogue Simulation}

We apply ThinkStation C30 workstation and Eviews7.2 to analogue simulation. The operational speed has improved significantly due to the progress of computers, which enables us to obtain more accurate discrete distribution of $\inf _{\lambda \epsilon \Lambda} t_{\widehat{\alpha}^{2}}(\lambda)$ in limited time. Lumsdaine and Papell (1997) obtain value of one-tailed test of 125 observations through 500 loop computations. Wang (2009) acquire value of one-tailed test of 312 observations through 1,000 loop computations. Chi and Wang (2013) gain value of one-tailed test of 149 observations through 2,000 loop computations.

Utilizing the operational advantage of ThinkStation C30 workstation, this paper takes $\mathrm{y}_{\mathrm{t}}=\varepsilon_{\mathrm{t}}$ as data generation process (DGP) to generate a time series randomly and obtain critical value from 130 samples. Consult Lumsdaine and Papell (1997) for details of the thought of operation and read Chi and Wang (2013) for details of operation steps. After generating 10,000 $\mathrm{t}\left[\lambda_{\text {inf }}^{i}\right]$ through loop computation 10,000 times, we obtain the discrete distribution of test statistics.

Make model CC and BB correspond to the results of OLS regression on equations (1) and (2) mentioned above respectively and thus we obtain the frequency distribution histogram of them as below.

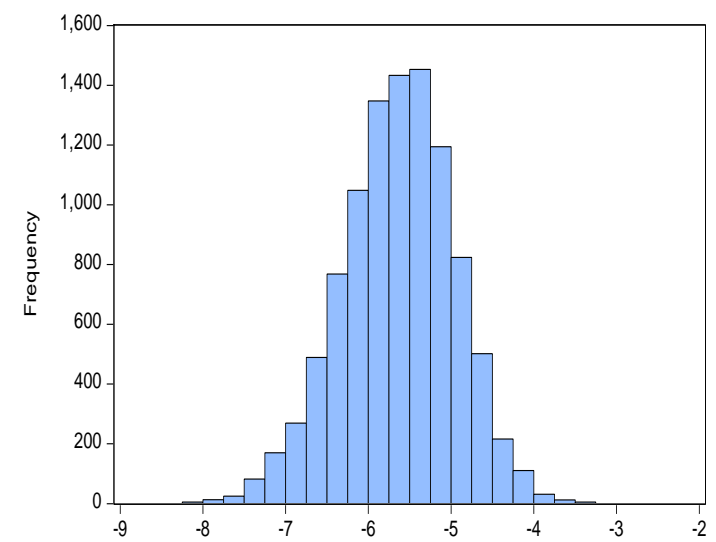

Figure 5. Frequency distribution histogram of model CC

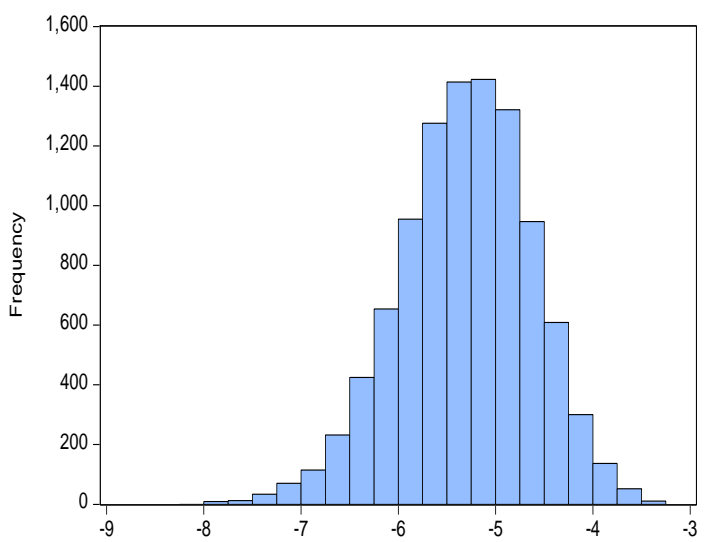

Figure 6. Frequency distribution histogram of model CB

Meanwhile, make model CA, BB, AB and AA correspond to the results of OLS regression on equations (3) to (6) mentioned above respectively and thus we obtain the frequency distribution histogram respectively.

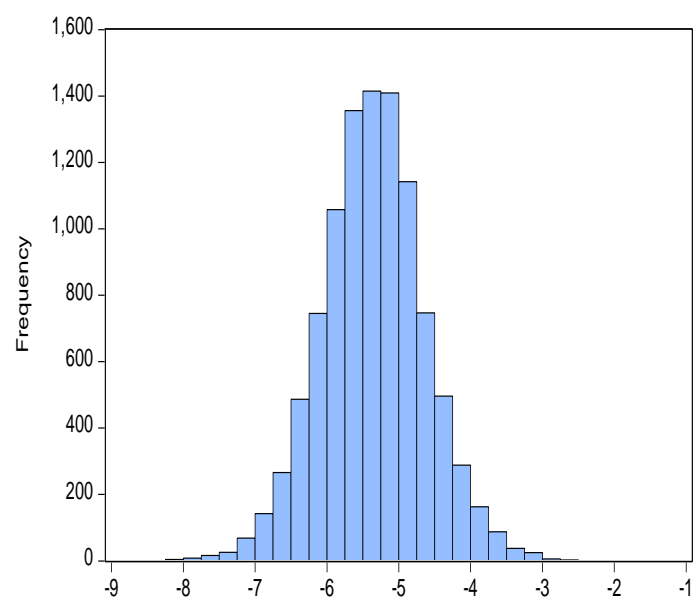

Figure 7. Frequency distribution histogram of model CA

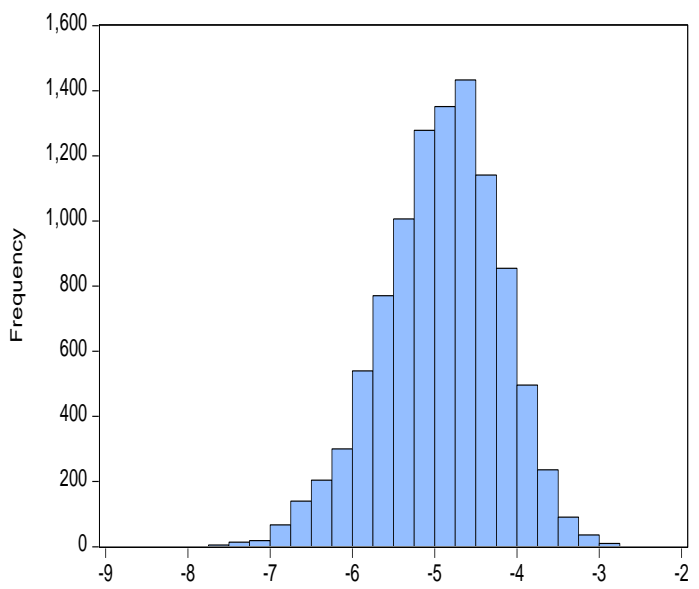

Figure 8. Frequency distribution histogram of model BB 

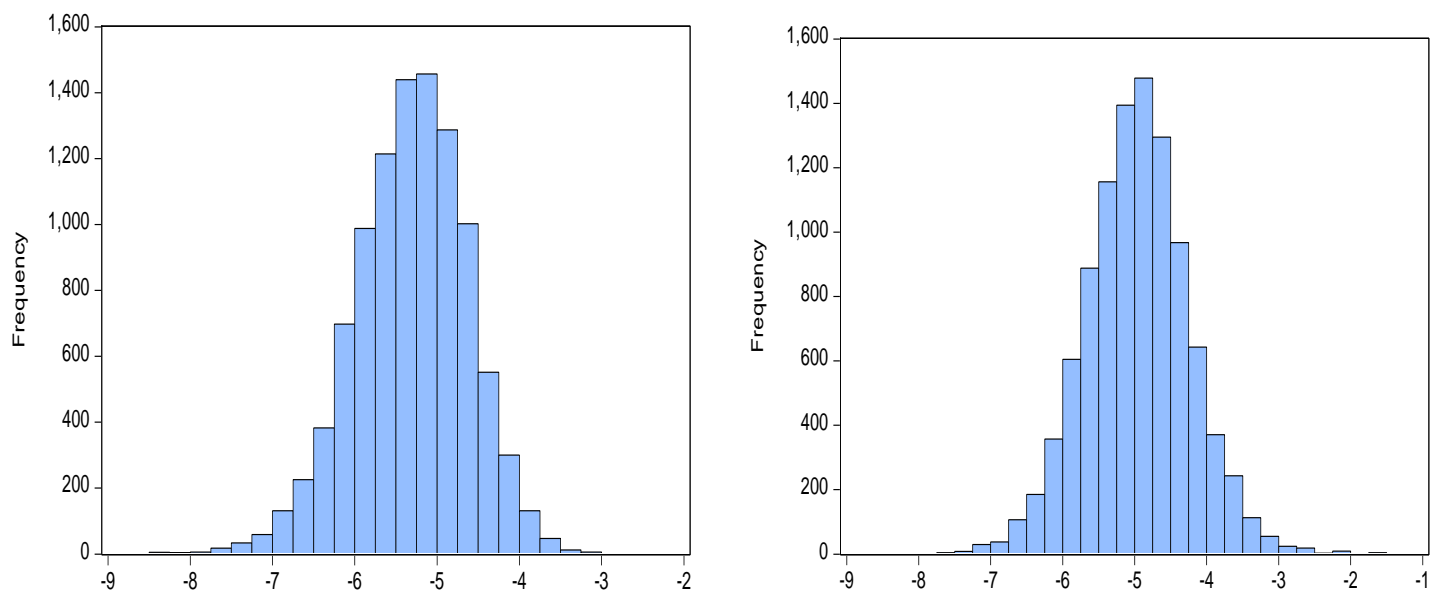

Figure 9. Frequency distribution histogram of model AB Figure 10. Frequency distribution histogram of model AA

Hence, we obtain the value of one-tailed test of multiple break points from the $1 \%-99 \%$ critical value of 130 samples.

Table 1. Critical Value of Multiple Break Points Test

\begin{tabular}{ccccccc}
\hline Model & $\mathbf{C C}$ & $\mathbf{C B}$ & $\mathbf{C A}$ & $\mathbf{B B}$ & $\mathbf{A B}$ & $\mathbf{A A}$ \\
\hline Computation times & 10,000 & 10,000 & 10,000 & 10,000 & 10,000 & 130 \\
\hline Sample size & 130 & 130 & 130 & 130 & -000 \\
\hline $\mathbf{1 \%}$ & -7.320183 & -7.084234 & -7.052203 & -6.776022 & -7.078229 & -6.692162 \\
\hline $\mathbf{2 . 5 \%}$ & -7.049908 & -6.736004 & -6.776993 & -6.502054 & -6.769831 & -6.413017 \\
\hline $\mathbf{5 \%}$ & -6.795680 & -6.477115 & -6.524501 & -6.200404 & -6.478599 & -6.141831 \\
\hline $\mathbf{1 0 \%}$ & -6.520491 & -6.208606 & -6.255961 & -5.868878 & -6.190558 & -5.880648 \\
\hline $\mathbf{1 5 \%}$ & -6.335007 & -6.017724 & -6.078950 & -5.679225 & -6.021212 & -5.699498 \\
\hline $\mathbf{5 0 \%}$ & -5.608722 & -5.283885 & -5.353501 & -4.884376 & -5.285213 & -4.960799 \\
\hline $\mathbf{8 5 \%}$ & -4.946337 & -4.615531 & -4.647394 & -4.189712 & -4.626997 & -4.256753 \\
\hline $\mathbf{9 0 \%}$ & -4.788531 & -4.461178 & -4.452313 & -4.044015 & -4.485394 & -4.082606 \\
\hline $\mathbf{9 5 \%}$ & -4.582327 & -4.249565 & -4.161298 & -3.825642 & -4.252519 & -3.780298 \\
\hline $\mathbf{9 7 . 5 \%}$ & -4.368729 & -4.058258 & -3.883751 & -3.637018 & -4.066479 \\
\hline $\mathbf{9 9 \%}$ & -4.139731 & -3.847592 & -3.586279 & -3.447236 & -3.838921 \\
\hline
\end{tabular}

Note: DGP: $\Delta \mathrm{y}_{\mathrm{t}}=\varepsilon_{\mathrm{t}}$

\section{Empirical Results on Structural Change with Multiple Break Points}

\subsection{ADF Test}

For unit root series, differencing operation changes the general structure in data generation process and make differencing series become stationary. However, for stationary series with multiple trends, the effect of differencing operation on data generation process is uncertain because it can only generate intercept and shift in stationary trends or eliminate time trend but not change the general structure in data generation process (Chi and Wang, 2013). It is of a great necessity to apply unit root test to the stock indexes of SME Board before we conduct structural change with multiple break points test because the result of structural change test will be stationary if time series show stationary process under traditional unit root test. We are supposed to perform the following abrupt structural change test only if the result of traditional unit root test is non-stationary time series. In other words, the purpose of structural change test is to remove the potential issue of false identification of time series when applying traditional unit root test. 
Utilize the method of traditional unit root test, the consequence of stationarity test using nominal stock price indexes without eliminating inflation factor is as below.

Table 2. Result of ADF test on small and medium-sized enterprise stock indexes

\begin{tabular}{|c|c|c|c|c|c|c|}
\hline \multirow[t]{2}{*}{ Categories } & \multirow[t]{2}{*}{ Series } & \multirow[t]{2}{*}{ Test form } & \multirow[t]{2}{*}{$\mathrm{t}$-Statistic } & \multicolumn{3}{|c|}{ Test critical values } \\
\hline & & & & $1 \%$ level & $5 \%$ level & $10 \%$ level \\
\hline \multirow{6}{*}{$\begin{array}{c}\text { Nominal stock } \\
\text { indexes }\end{array}$} & LSSPI & $(\mathrm{c}, \mathrm{t}, 0)$ & -2.618369 & -4.030729 & -3.445030 & -3.147382 \\
\hline & LSSCI & $(\mathrm{c}, \mathrm{t}, 0)$ & -2.375955 & -4.030729 & -3.445030 & -3.147382 \\
\hline & LSPMI & $(\mathrm{c}, \mathrm{t}, 0)$ & -2.646479 & -4.030729 & -3.445030 & -3.147382 \\
\hline & D(LSSPI) & $(\mathrm{c}, 0,1)$ & -10.63437 & -3.482035 & -2.884109 & -2.578884 \\
\hline & D(LSSCI) & $(\mathrm{c}, 0,1)$ & -10.46862 & -3.482035 & -2.884109 & -2.578884 \\
\hline & D(LSPMI) & $(\mathrm{c}, 0,1)$ & -10.49533 & -3.482035 & -2.884109 & -2.578884 \\
\hline \multirow{6}{*}{$\begin{array}{c}\text { Real stock } \\
\text { indexes }\end{array}$} & LRSSPI & $(\mathrm{c}, \mathrm{t}, 0)$ & -1.950472 & -4.030729 & -3.445030 & -3.147382 \\
\hline & LRSSCI & $(\mathrm{c}, \mathrm{t}, 0)$ & -1.760458 & -4.030729 & -3.445030 & -3.147382 \\
\hline & LRSPMI & $(\mathrm{c}, \mathrm{t}, 0)$ & -1.947453 & -4.030729 & -3.445030 & -3.147382 \\
\hline & D(LRSSPI) & $(\mathrm{c}, 0,1)$ & -10.54923 & -3.482035 & -2.884109 & -2.578884 \\
\hline & D(LRSSCI) & $(\mathrm{c}, 0,1)$ & -10.39280 & -3.482035 & -2.884109 & -2.578884 \\
\hline & D(LRSPMI) & $(\mathrm{c}, 0,1)$ & -10.48690 & -3.482035 & -2.884109 & -2.578884 \\
\hline
\end{tabular}

The results of ADF unit root test indicate that both nominal stock indexes (LSSPI, LSSCI and LSPMI) and real stock indexes (LRSSPI, LRSSCI and LRSPMI) are I (1) processes at $1 \%$ significance level.

\subsection{Multi Structural Change Test}

In the equations (1) - (6) in preceding part of the text, $\mathrm{k}$ is lag length and the function of $\mathrm{k}$ is to eliminate the effect of potential random disturbance if it is not independent and identical distributed. The value of $\mathrm{k}$ is decided by the significance of estimator $c_{k}^{i}$. Papell and Prodon (2007) set the t statistics of estimator $c_{k}^{i}$ as 1.645. This paper will use the same value as the standard of significance. We set $k_{\max }=12$ and apply model AA, CC and CA (equations (1) - (3)) used by Lumsdaine and Papell (1997) to the indexes series of SME Board and perform the structural change test. The results are shown in Table 3.

Meanwhile, we employ the supplementary approach raised by Wang et al (2009) which is the extended model (equations (4) to (6)) to conduct the structural change test on series mentioned above and the consequences are listed in Table 4. 
Table 3. Result of structural change test on nominal small and medium-sized enterprise stock indexes based on LP model

\begin{tabular}{|c|c|c|c|c|c|c|c|c|c|c|c|c|c|}
\hline series & model & $\hat{\alpha}$ & $t_{\widehat{\alpha}}$ & breakpoints & $\hat{\theta}$ & $\widehat{\omega}$ & $t_{\hat{\theta}}$ & $\mathrm{t}_{\widehat{\omega}}$ & $\hat{\gamma}$ & $\widehat{\Psi}$ & $\mathrm{t}_{\bar{\gamma}}$ & $t_{\widehat{\Psi}}$ & $\mathrm{k}$ \\
\hline \multirow[t]{6}{*}{ lsspi } & AA & -0.403489 & -5.361396 & 2012M06 & -0.125604 & & -3.019474 & & & & & & 11.00000 \\
\hline & & & & 2015M01 & & 0.066453 & & 2.117707 & & & & & \\
\hline & $\mathrm{CC}$ & -0.550595 & -6.207849 & 2010M07 & 0.177432 & & 3.830412 & & -0.005831 & & -3.135017 & & 12.00000 \\
\hline & & & & 2014M06 & & 0.134220 & & 3.266544 & & 0.008997 & & 3.751647 & \\
\hline & $\mathrm{CA}$ & -0.424940 & -5.833874 & 2010M07 & 0.102592 & & 2.586205 & & -0.003554 & & -2.257509 & & 11.00000 \\
\hline & & & & 2015M01 & & 0.197025 & & 4.207462 & & & & & \\
\hline \multirow[t]{6}{*}{ lssci } & AA & -0.285730 & -5.199775 & 2011M11 & -0.150956 & & -3.325509 & & & & & & 7.000000 \\
\hline & & & & 2008M06 & & -0.110948 & & -2.801917 & & & & & \\
\hline & $\mathrm{CC}$ & -0.526197 & -5.880106 & 2013M06 & -0.025758 & & -0.597302 & & 0.014653 & & 4.798431 & & 12.00000 \\
\hline & & & & 2010M07 & & 0.212654 & & 3.778088 & & -0.006021 & & -2.686784 & \\
\hline & CA & -0.296084 & -5.396412 & 2011M09 & -0.177189 & & -3.617087 & & -0.002283 & & -1.539364 & & 7.000000 \\
\hline & & & & 2008M06 & & -0.165637 & & -2.906947 & & & & & \\
\hline \multirow[t]{6}{*}{ lspmi } & AA & -0.404696 & -5.313358 & 2015M01 & 0.096557 & & 2.745242 & & & & & & 11.00000 \\
\hline & & & & 2012M06 & & -0.137909 & & -3.071446 & & & & & \\
\hline & $\mathrm{CC}$ & -0.515859 & -5.861707 & 2010M07 & 0.160699 & & 3.344392 & & -0.006298 & & -3.088863 & & 12.00000 \\
\hline & & & & 2014M06 & & 0.146389 & & 3.292786 & & 0.010121 & & 3.700605 & \\
\hline & $\mathrm{CA}$ & -0.301112 & -5.541863 & 2011M09 & -0.177240 & & -3.675320 & & -0.002657 & & -1.784354 & & 7.000000 \\
\hline & & & & 2008M06 & - & 0.151825 & & -2.755554 & & & & & \\
\hline
\end{tabular}

Table 4. Result of structural change test on nominal small and medium-sized enterprise stock indexes based on extended LP model

\begin{tabular}{|c|c|c|c|c|c|c|c|c|c|c|c|c|c|}
\hline series & model & $\widehat{\alpha}$ & $\mathrm{t}_{\widehat{\alpha}}$ & breakpoints & $\hat{\theta}$ & $\widehat{\omega}$ & $\mathrm{t}_{\widehat{\theta}}$ & $\mathrm{t}_{\widehat{\omega}}$ & $\hat{\gamma}$ & $\widehat{\Psi}$ & $\mathrm{t}_{\bar{\gamma}}$ & $t_{\hat{\Psi}}$ & $\mathrm{k}$ \\
\hline \multirow[t]{6}{*}{ lsspi } & \multirow[t]{2}{*}{ BB } & \multirow[t]{2}{*}{-0.377635} & \multirow[t]{2}{*}{-5.002575} & 2011M03 & -0.125604 & & -3.019474 & & -0.007340 & & -3.025328 & & \multirow[t]{2}{*}{11.00000} \\
\hline & & & & 2013M05 & & 0.066453 & & 2.117707 & & 0.007626 & & 3.156601 & \\
\hline & \multirow[t]{2}{*}{$\mathrm{CB}$} & \multirow[t]{2}{*}{-0.470824} & \multirow[t]{2}{*}{-5.982421} & 2010M07 & 0.170778 & & 3.489564 & & -0.007407 & & -3.521763 & & \multirow[t]{2}{*}{11.00000} \\
\hline & & & & 2013M04 & & 0.134220 & & 3.266544 & & 0.010845 & & 4.364631 & \\
\hline & \multirow[t]{2}{*}{$\mathrm{AB}$} & \multirow[t]{2}{*}{-0.366890} & \multirow[t]{2}{*}{-5.268909} & 2015M01 & 0.154296 & & 3.504620 & & -0.003554 & & -2.257509 & & \multirow[t]{2}{*}{11.00000} \\
\hline & & & & 2010M12 & & 0.197025 & & 4.207462 & & -0.004490 & & -2.886791 & \\
\hline \multirow[t]{6}{*}{ lssci } & \multirow[t]{2}{*}{ BB } & \multirow[t]{2}{*}{-0.330983} & \multirow[t]{2}{*}{-4.667125} & 2013M05 & -0.150956 & & -3.325509 & & 0.008504 & & 3.139204 & & \multirow[t]{2}{*}{11.00000} \\
\hline & & & & $2011 \mathrm{M} 03$ & & -0.110948 & & -2.801917 & & -0.006558 & & -2.672635 & \\
\hline & \multirow[t]{2}{*}{$\mathrm{CB}$} & \multirow[t]{2}{*}{-0.526031} & \multirow[t]{2}{*}{-5.922802} & 2010M07 & 0.211369 & & 3.812942 & & -0.005945 & & -2.936392 & & \multirow[t]{2}{*}{12.00000} \\
\hline & & & & 2013M08 & & 0.212654 & & 3.778088 & & 0.014619 & & 4.798130 & \\
\hline & \multirow[t]{2}{*}{$\mathrm{AB}$} & \multirow[t]{2}{*}{-0.261175} & \multirow[t]{2}{*}{-5.086320} & 2009M09 & 0.133795 & & 2.875029 & & -0.002283 & & -1.539364 & & \multirow[t]{2}{*}{7.000000} \\
\hline & & & & 2013M04 & & -0.165637 & & -2.906947 & & 0.006136 & & 3.400790 & \\
\hline \multirow[t]{6}{*}{ lspmi } & \multirow[t]{2}{*}{ BB } & \multirow[t]{2}{*}{-0.357808} & \multirow[t]{2}{*}{-4.888511} & $2012 \mathrm{M} 12$ & 0.096557 & & 2.745242 & & 0.009956 & & 3.352402 & & \multirow[t]{2}{*}{11.00000} \\
\hline & & & & $2011 \mathrm{M} 03$ & & -0.137909 & & -3.071446 & & -0.009395 & & -3.116934 & \\
\hline & \multirow[t]{2}{*}{$\mathrm{CB}$} & \multirow[t]{2}{*}{-0.531718} & -5.992917 & 2010M07 & 0.184558 & & 3.599511 & & -0.007503 & & -3.390787 & & 12.00000 \\
\hline & & & & 2013M08 & & 0.146389 & & 3.292786 & & 0.013765 & & 4.748882 & \\
\hline & $\mathrm{AB}$ & -0.244780 & -5.031345 & 2009M09 & 0.130563 & & 2.755524 & & -0.002657 & & -1.784354 & & 7.000000 \\
\hline & & & & $2012 \mathrm{M} 12$ & & -0.151825 & & -2.755554 & & 0.005150 & & 3.037861 & \\
\hline
\end{tabular}


Column 4 in Tables 3 and 4 are $t$ statistics of estimator $\alpha$ and all absolute value of $t_{\widehat{\alpha}}$ are smaller than the corresponding absolute value of $10 \%$ critical value in Table 1 . Hence, we cannot reject the null hypotheses that LSSPI, LSSCI and LSPMI are unit roots at $90 \%$ confidence level.

The tests above do not take inflation into consideration. In pursuance of enhancing the power of the tests, we use China Commodity Price Index (CCPI) published by Ministry of Commerce of China to eliminate the inflation factor and obtain real stock indexes series LRSSPI, LRSSCI and LRSPMI. Using the same LP model and extended LP model to perform the structural change tests, we achieve the test results in Tables 5 and 6 .

Table 5. Result of structural change test on real small and medium-sized enterprise stock indexes based on LP model

\begin{tabular}{|c|c|c|c|c|c|c|c|c|c|c|c|c|c|}
\hline series & model & $\widehat{\alpha}$ & $\mathrm{t}_{\widehat{\alpha}}$ & breakpoints & $\hat{\theta}$ & $\widehat{\omega}$ & $\mathrm{t}_{\hat{\theta}}$ & $\mathrm{t}_{\widehat{\omega}}$ & $\hat{\gamma}$ & $\widehat{\Psi}$ & $t_{\widehat{\gamma}}$ & $t_{\Psi}$ & $\mathrm{k}$ \\
\hline \multirow[t]{6}{*}{ lrsspi } & AA & -0.364019 & -5.537877 & 2011M09 & -0.134080 & & -3.149277 & & & & & & 11.00000 \\
\hline & & & & 2015M01 & & 0.165626 & & 3.755027 & & & & & \\
\hline & $\mathrm{CC}$ & -0.274343 & -5.045174 & 2014M08 & 0.211499 & & 4.838575 & & 0.001228 & & 0.536727 & & 11.00000 \\
\hline & & & & 2008M11 & & 0.256343 & & 4.792945 & & 0.012762 & & 2.477120 & \\
\hline & $\mathrm{CA}$ & -0.257386 & -5.836134 & 2008M11 & 0.258688 & & 4.870174 & & 0.013637 & & 2.800072 & & 11.00000 \\
\hline & & & & 2014M08 & & 0.219765 & & 5.391118 & & & & & \\
\hline \multirow[t]{6}{*}{ lrssci } & AA & -0.316034 & -5.203102 & 2011M09 & -0.123944 & & -2.853677 & & & & & & 11.00000 \\
\hline & & & & 2015M01 & & 0.178469 & & 3.620381 & & & & & \\
\hline & $\mathrm{CC}$ & -0.254736 & -4.707027 & 2014M08 & 0.226147 & & 4.846279 & & 0.001620 & & 0.639781 & & 11.00000 \\
\hline & & & & 2008M11 & & 0.276065 & & 4.838588 & & 0.015628 & & 2.907454 & \\
\hline & $\mathrm{CA}$ & -0.232775 & -5.579857 & 2008M11 & 0.278939 & & 4.918590 & & 0.016495 & & 3.180777 & & 11.00000 \\
\hline & & & & 2014M08 & & 0.235146 & & 5.300463 & & & & & \\
\hline \multirow[t]{6}{*}{ lrspmi } & AA & -0.349393 & -5.329858 & 2011M09 & -0.143562 & & -3.157569 & & & & & & 11.00000 \\
\hline & & & & 2015M01 & & 0.181575 & & 3.740436 & & & & & \\
\hline & $\mathrm{CC}$ & -0.325054 & -4.622802 & 2011M09 & -0.150596 & & -3.269098 & & 0.000512 & & 0.292813 & & 11.00000 \\
\hline & & & & 2015M01 & & 0.207373 & & 3.533833 & & -0.003970 & & -1.154158 & \\
\hline & $\mathrm{CA}$ & -0.237480 & -5.490224 & 2008M11 & 0.264264 & & 4.708720 & & 0.014092 & & 2.674308 & & 11.00000 \\
\hline & & & & 2014M08 & & 0.229003 & & 5.174805 & & & & & \\
\hline
\end{tabular}


Table 6. Result of structural change test on real small and medium-sized enterprise stock indexes based on extended LP model

\begin{tabular}{|c|c|c|c|c|c|c|c|c|c|c|c|c|c|}
\hline series & model & $\widehat{\alpha}$ & $\mathrm{t}_{\widehat{\alpha}}$ & breakpoints & $\hat{\theta}$ & $\widehat{\omega}$ & $\mathrm{t}_{\hat{\theta}}$ & $\mathrm{t}_{\widehat{\omega}}$ & $\hat{\gamma}$ & $\widehat{\Psi}$ & $\mathrm{t}_{\widehat{\gamma}}$ & $t_{\widehat{\Psi}}$ & $\mathrm{k}$ \\
\hline \multirow[t]{5}{*}{ lrsspi } & BB & -0.323772 & -4.797800 & $2012 \mathrm{M} 12$ & -0.134080 & & -3.149277 & & 0.011776 & & 3.656903 & & 11.00000 \\
\hline & $\mathrm{CB}$ & -0.362966 & -5.084711 & 2010M07 & 0.097071 & & 1.975654 & & -0.009845 & & -3.497312 & & 11.00000 \\
\hline & & & & 2012M12 & & 0.256343 & & 4.792945 & & 0.014512 & & 3.938621 & \\
\hline & $\mathrm{AB}$ & -0.261122 & -5.061038 & 2008 M11 & 0.162804 & & 4.190114 & & 0.013637 & & 2.800072 & & 11.00000 \\
\hline & & & & 2013M03 & & 0.219765 & & 5.391118 & & 0.007203 & & 4.245544 & \\
\hline \multirow[t]{8}{*}{ lrssci } & BB & -0.279314 & -4.514158 & 2010M11 & -0.123944 & & -2.853677 & & -0.007710 & & -2.732085 & & 11.00000 \\
\hline & & & & 2012M12 & & 0.178469 & & & & 0.011434 & & 3.420454 & \\
\hline & & & & & & & & 3.620381 & & & & & \\
\hline & $\mathrm{CB}$ & -0.230912 & -4.973212 & 2008M11 & 0.258002 & & 4.405480 & & 0.010769 & & 2.051985 & & 11.00000 \\
\hline & & & & 2012M12 & & 0.276065 & & 4.838588 & & 0.007724 & & 4.366939 & \\
\hline & $\mathrm{AB}$ & -0.234938 & -4.788954 & 2008M11 & 0.164996 & & 4.080927 & & 0.016495 & & 3.180777 & & 11.00000 \\
\hline & & & & 2013M02 & & 0.235146 & & & & 0.007856 & & 4.227892 & \\
\hline & & & & & & & & 5.300463 & & & & & \\
\hline \multirow[t]{5}{*}{ lrspmi } & BB & -0.310132 & -4.549396 & 2012M12 & -0.143562 & & -3.157569 & & 0.012661 & & 3.540142 & & 11.00000 \\
\hline & & & & 2010M11 & & 0.181575 & & 3.740436 & & -0.009391 & & -3.007144 & \\
\hline & $\mathrm{CB}$ & -0.234274 & -4.831411 & 2008M11 & 0.242644 & & 4.180517 & & 0.008128 & & 1.495975 & & 11.00000 \\
\hline & & & & $2012 \mathrm{M} 12$ & & 0.207373 & & 3.533833 & & 0.007432 & & 4.170946 & \\
\hline & $\mathrm{AB}$ & -0.239450 & -4.921011 & 2008M11 & 0.182557 & & 4.330847 & & 0.014092 & & 2.674308 & & \\
\hline
\end{tabular}

Tables 5 and 6 reveal that structural change is likely to happen in points including 2008M11. Nevertheless, we discover that, model BB, CB and AB cannot reject the null hypotheses that LRSSPI, LRSSCI and LRSPMI are unit roots at $90 \%$ confidence level based on the results of critical values of multiple break points tests in Table 1 and $t$ statistics of estimator $s p_{t-1}$ in Tables 5 and 6. Therefore, SSPI, SPMI and SSCI follow unit root process after eliminating inflation factor.

\section{Conclusion}

This article employs multiple break points test to study the volatility in small and medium-sized enterprise stock prices in China. Based on critical value of Monte Carlo Simulation breakpoint test, we conduct the structural change tests using SZSE SME Price Index (SSPI), SZSE SME Comp Index (SSCI) and SME Prime Mkt Index (SPMI). Simultaneously, we test the real series of these series mentioned above after we use China Commodity Price Index (CCPI) to eliminate the inflation factor. We find the null hypotheses that SSPI, SSCI and SPMI follow unit root process cannot be rejected at $90 \%-99 \%$ confidence level. Specifically, the overall volatility in small and medium-sized enterprise stock prices follows a random walk process and is not characterised by mean reversion.

The SME Board in A-share market is an important composition of China multi-level capital market. In June 2004, the first batch enterprises like Zhejiang NHU Co., Ltd (NHU) et al start to be traded in the secondary market of SME Board. The steps of financing through equity market have been speeding up since June 2005 . There are 848 enterprises issue in SME Board until 18th April 2017. The result that SSPI, SSCI and SPMI follow unit root process reveal any imposition of macroeconomic policies and change of equity market environment cannot change how stock prices grow in SME Board. For example, major events like financial crisis in 2008, policy bailout in 2015 do not have structural change effect on SSPI, SSCI and SPMI. Expressly, the rise and fall of stocks in SME Board depend on the supply and demand situation in equity market as well as macroeconomic situation in the long term, while major events like policy bailout in June 2015 are ineffective because they are already offset by other factors. The 
long-run growth of stock prices in SME Board depends on the supply and demand situation in equity market as well as the growth of national economy but has no connection with other events.

The conclusion and policy suggestion in this article are based on the test of multiple break points on SSPI, SSCI and SPMI. Listed companies in SME Board are on a small scale. In addition, the operation of SME Board follows rules of independent operation, independent supervise, independent stock code and independent indexes. Consequently, the overall volatility of stock prices in SME Board is different from other boards. It is necessary to do another study rather than apply the result of this study to other boards mechanically if we want to obtain the volatility of stock prices in the Main Board, Growth Enterprise Board et al in China.

\section{Acknowledgements}

We acknowledge the research supports of Guangdong Provincial Department of Science \& Technology via the Grant of Soft Science Research Project 2016A070705059. Meanwhile, we acknowledge the research supports of Shantou University via Grants NFC16009 and STF13012.

\section{References}

Andrews, D. W. K. (1993). Tests for parameter instability and structural change with unknown change point. Econometrica. 61, 821-856.

Balsara, N. J., Chen, G., \& Lin Z. (2007). The Chinese stock market: an examination of the random walk model and technical trading rules. Quarterly Journal of Business \& Economics, 46(2), 43-63.

Ben-David, D., Lumsdaine, R., \& D. Papell. (2003). Unit roots, postwar slowdowns and long-run growth: evidence from two structural breaks. Empirical Economics, 28, 303-319.

Borges, M. R. (2011). Random walk tests for the Lisbon stock market. Applied Economics, 43(5), 631-639. https://doi.org/10.1080/00036840802584935

Chang, K. P., \& Ting, K. S. (2000). A variance ratio test of the random walk hypothesis for Taiwan's stock market. Applied Financial Economics, 10, 525-32. https://doi.org/10.1080/096031000416406.

Chattopadhyay, S. (2016). An exploration into the predictability of stock prices in India: mean reversion vs. random walk. Money \& Finance, 85-128.

Chi, Q. S., \& Wang, Z. Q. (2013). Prices impacted by structural change in money supply. Economic Science. 1, $10-21$.

Chow, G. C. (1960). Tests of equality between sets of coefficients in Two linear regressions. Econometrica, 28, 591-605.

Chow, G. C. (2002). China's economic transformation. Blackwell Publishers, Oxford.

Clark, S. P., \& Coggin, T. D. (2011). Are U.S. stock prices mean-reverting? Some new tests using fractional integration models with overlapping data and structural breaks. Empirical Economics, 40(2), 373-391. https://doi.org/10.1007/s00181-010-0338-y

Dickey, D. A., \& W. A. Fuller. (1979). Distribution of the estimators for autoregressive time series with a unit root, Journal of the American Statistical Association, 74, 427-431.

Dickey, D. A., \& W. A. Fuller. (1981). Likelihood ratio statistics for autoregressive time series with a unit root. Econometrica, 49, 1057-1072.

Dsouza, J. J., \& Mallikarjunappa, T. (2015). Does the Indian stock market exhibit random walk? Paradigm, 19(1), 1-20. https://doi.org/10.1177/0971890715585197

Hooi H. L., \& Smyth, R. (2007). Do Asian stock markets follow a random walk? Evidence from LM unit root tests with one and two structural breaks. Review of Pacific Basin Financial Markets \& Policies, 10(1), 15-31.

Im, K. S., Lee, J., \& Tieslau, M. (2002). Panel LM unit root tests with level shifts, mimeo, Department of Economics, University of Central Florida.

Im, K. S., Pesaran, H., \& Shin, Y. (2003). Testing for unit roots in heterogeneous panels. Journal of Econometrics, 115, 53-74.

Lakshmi, V. D. M. V., \& Roy, B. (2012). Testing the random walk model in Indian stock markets. IUP Journal of Applied Finance, 18(2), 63-79.

Lo, W. A., \& MacKinlay, C. A. (1988). Stock market prices do not follow random walks: evidence from a simple 
specification test. Review of Financial Studies, 1(1), 41-66.

Lumsdaine, R. L., \& D. H. Papell. (1997). Multiple trend breaks and the unit-root hypothesis. The Review of Economics and Statistics, 79, 212-218.

Mishra, A., Mishra, V., \& Smyth, R. (2015). The random-walk hypothesis on the Indian stock market. Emerging Markets Finance \& Trade, 51(5), 879-892. https://doi.org/10.1080/1540496X.2015.1061380

Narayan, P. K. (2005). The structure of tourist expenditure in Fiji: evidence from unit-root structural break tests. Applied Economics, 37, 1157-1161. https://doi.org/10.1080/00036840500109373

Narayan, P. K., \& Smyth, R. (2005). Are OECD stock prices characterized by a random walk? Evidence from sequential trend break and panel data models. Applied Financial Economics, 15, 547-556. https://doi.org/10.1080/0960310042000314223

Narayan P. K., \& Smyth R. (2006). Random walk versus multiple trend breaks in stock prices: evidence from 15 European markets. Applied Financial Economics Letters, 2(1), 1-7. https://doi.org/10.1080/17446540500424784

Nelson, C. R., \& C. Plosser. (1982). Trends and random walks in macroeconomic time series: some evidence and implications. Journal of Monetary Economics, 10, 139-162.

Papell, D. H., \& R. Prodan. (2007). Restricted structural change and the unit root hypothesis. Economic Inquiry, 45, 834-853.

Perron, P. (1988). Trends and random walks in macroeconomic time series: further evidence from a new approach. Journal of Economic Dynamics and Control, 12, 473-496.

Perron, P. (1989). The great crash, the oil price shock, and the unit-root hypothesis. Econometrica, 57, 1361-1401.

Perron, P. (1997). Further evidence on breaking trend functions in macroeconomic variables. Journal of Econometrics, 80, 355-385.

Pesaran, H. (2007). A simple panel unit root test in the presence of cross section dependence. Journal of Applied Econometrics, 22(2), 265-312.

Shen, X., \& Holmes, M. J. (2014). Do Asia-Pacific stock prices follow a random walk? A regime-switching perspective. Applied Economics Letters, 21(3), 189-195. https://doi.org/10.1080/13504851.2013.848016

Shiller, R. J., \& P. Perron. (1985). Testing the random walk yypothesis: power versus frequency of observation. Economics Letters, 18, 381-386.

Shirvani, H., \& Delcoure, N. V. (2016). The random walk in the stock prices of 18 OECD countries: Some robust panel-based integration and cointegration tests. Journal of Economic Studies, 43(4), 598-608. https://doi.org/10.1108/JES-03-2015-0053

Wang, Z.Q., Tian, Y. B., \& Wang, S.Y. (2009). On structural change in China's imports and exports. Systems Engineering-Theory \& Practice, 29(2), 10-17.

Zivot, E., \& D. Andrews. (1992). Further evidence on the great crash, the oil-price shock, and the unit-root hypothesis. Journal of Business and Economic Statistics, 10, 251-270. 


\section{Appendix. Empirical Log Survivor}
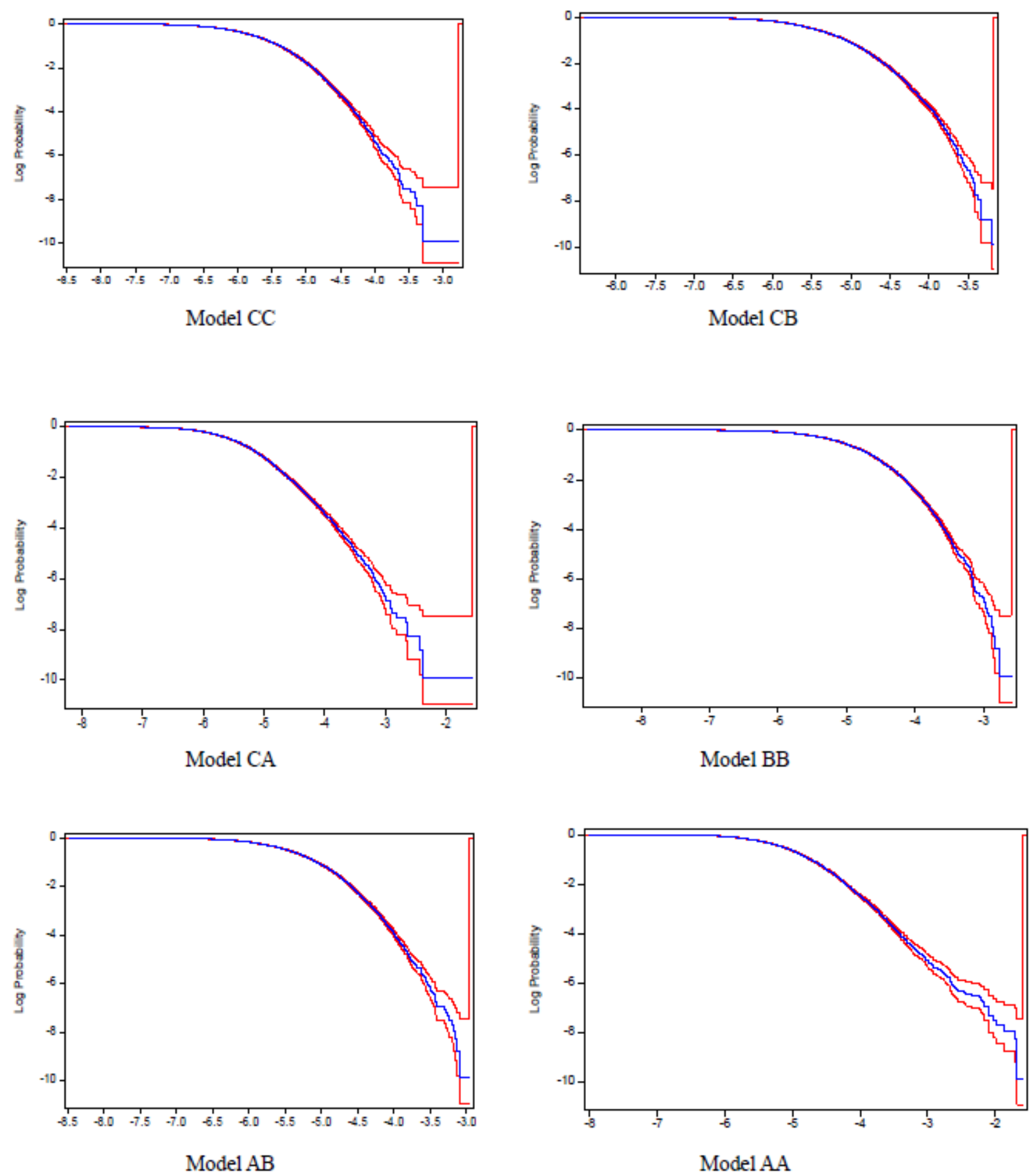